\title{
A Dança Sagrada: uma discussão de memória Bergsoniana em movimento
}

\author{
Wermerson Meira Silva ${ }^{1}$ \\ Universidade Estadual do Sudoeste da Bahia
}

João Diogenes Ferreira dos Santos 2 iid

Universidade Estadual de Feira de Santana

\section{Artigos livres | Free articles | Articulos libres \\ DOI do artigo: 10.22481/odeere.v6i2.9784 \\ RESUMO}

Este artigo tem por objetivo trazer a dança sagrada na memória Bergosoniana através das comunidades de terreiros, compreendida como expressões corporais representadas através da materialiação dos corpos e memória no que diz respeito ao movimento, na dança e toque da Orixá Oxum. Embalados pela problemática de como a dança sagrada nos terreiros de candomblé da nação Ketu/Nagô reflete a memória em movimento trazida por Bergson? Com isso propomos um recorte da memória com base em Bergson que nos ajudam á situar a memória em movimentos ancestrais através dos acontecimentos que resultam nas relações sociais de grupos que contribuem através de depoimentos, contatos, lembranças, expressões e recordações (re) construídas sobre um fundamento da dança. Como metodologia de pesquisa, fizemos uma busca no acervo utilizando o referencial teórico de Bergson em as suas publicações correntes na qual, concluímos que a memória exerce papel fundamental para preservação e também para estudos e pesquisas deste universo sagrado.

Palavras chave: Memória; Bergson; Oxum; Corpo; Candomblé.

\section{The Sacred Dance: a discussion of Bergsonian Memory in motion ABSTRACT}

This article aims to bring sacred dance into Bergosonian memory through communities of terreiros, understood as bodily expressions represented through the materialization of bodies and memory with regard to movement, dance and touch by Oxum. Rocked by the issue of how the sacred dance in the candomble terreiros of the Ketu/Nagô nation reflects the moving memory brought by Bergson? With that I propose a memory clipping based on Bergson that help us to locate memory in ancestral movements through the events that result in the social relations of groups that contribute through testimonies, contacts, memories, expressions and recollections (re)constructed on a foundation of the dance. As a research methodology, we searched the collection using Bergson's theoretical framework in his current publications. We conclude that memory plays a fundamental role for preservation and also for studies and research of this sacred universe.

Keywords: Memory; Bergson; Oshun; Body; Candomblé.

Submetido em: 29/10/2021 | Aceito em: 24/12/2021

1 Doutorando no Programa de Pós-Graduação em Memória: Linguagem e Sociedade - [PPGMLS] Mestre no Programa de Pós-graduação em Educação e Diversidade- [MPPED-UNEB], Pós Graduado em Tradução e Interpretação de Libras- [Universidade Paulista- 2012]. Graduado no curso de Licenciatura em LETRAS/LIBRAS- [Universidade Federal da Paraíba - UFPB - 2016], Graduado no curso de Licenciatura em Pedagogia- [Universidade Paulista- 2011]. Proficiente em Tradução e Interpretação da Língua Brasileira de Sinais - LSB - [MEC - 2007] e Proficiente para o Uso e o Ensino da Língua Brasileira de Sinais - LSB - [MEC -2008]. E-mail: wermerson@vesb.edu.br

2 Possui graduação em História pela Universidade Estadual de Feira de Santana (1995), mestrado em Sociologia pela Universidade Federal da Paraíba (1998) e doutorado em Ciências Sociais, Pontifícia Universidade Católica de São Paulo (2007). Atualmente é professor titular, nível B, da Universidade Estadual de Feira de Santana, pesquisador do Museu Pedagógico e docente do Programa de Pós-Graduação em Memória, Linguagem e Sociedade da Universidade Estadual do Sudoeste da Bahia. Tem experiência na área de Sociologia, com ênfase em Sociologia Política, atuando principalmente nos seguintes temas: violência contra crianças, adolescentes e jovens, gênero, diversidade sexual, cultura política, memória e educação. E-mail: jdiogenes69@gmail.com 


\section{INTRODUÇÃO}

Este artigo advém de um trabalho realizado como avaliação na disciplina Memória em Bergson ministrada no Programa de Pós-Graduação em Memória: Linguagem e Sociedade da Universidade Estadual do Sudoeste da Bahia (UESB) no curso de doutoramento para discentes no período de 2019, tendo foco na memória e ancestralidade, categorias que utilizamos na pesquisa para a conclusão da tese.

Esse trabalho tem como objetivo pautar a dança sagrada na memória Bergosoniana através das comunidades de terreiros, compreendidas como expressões corporais representadas através do movimento, na dança e toque da Orixá Oxum - Orixá das águas que é a dona do rio que leva seu nome, na cidade de Oxogbo, na região da Nigéria. Embora outras Yabás interligam nas águas doces, é Oxum considerada a mãe das águas doces, serenas e tranquilas. Dividindo com lemanjá o poder da maternidade. A fertilidade lhe é atribuída, com a ajuda de Exu, responsável pela concepção do ato sexual. É de Oxum a atribuição de zelar pelo crescimento do feto no útero materno, como dos bebês recém-nascidos. "Oxum é, portanto, a mãe, aquela que protege, nutre e cura. É a mulher em sua plenitude" (AUGRAS, 2008, p.154).

Então surge a seguinte problemática: Como a dança sagrada nos terreiros de candomblé da nação ketu/Nagô reflete a memória em movimento trazida por Bergson? Buscamos essa resposta por meio de referências fundamentada na teoria de Bergson que aborda sobre a memória em movimento.

O poder de Oxum é representado em seu título lyalodê, ou seja, a Rainha de todas as mulheres, ela que ocupa o cargo mais importante entre as mulheres da cidade, além disso, os seus axés são constituídos por pedras no fundo do rio Oxum, de joias de ouro e de um pente de tartaruga. Oxum também é identificada como nossa mãe ancestral estando associada à lyami Agba que significa as mães da fortuna e da felicidade, a dona da maior célula viva, o ovo que representa o nascimento (VERGER, 1997).

Oxum está viva através dos ritos e mitos preservados dentro dos terreiros de candomblés através da memória e movimento. Dessa forma, colocamos em discussão a matéria e memória com base nos estudos de Bergson que nos ajudam a situar o campo da memória sendo relevante que haja um pensador que paute á dimensão da memória e á sua relação com a dança no conjunto diverso de 
acontecimentos com base nas relações sociais de grupos através de depoimentos, contatos, lembranças, expressões, recordações (re) construídas sobre um fundamento comum.

\section{CAMINHOS DA MEMÓRIA}

Percebo bem de que maneira as imagens exteriores influem sobre a imagem que chamo meu corpo: elas Ihes transmitem movimento. $E$ vejo também de que maneira este corpo influi sobre as imagens exteriores; ele Ihes restitui movimento. (BERGSON, 1999, p. 171).

Introduziremos os caminhos da memória com o Filósofo francês, Henri Bergson que nasceu em Paris, a 18 de outubro de 1859 e morreu na mesma cidade no dia 4 de janeiro de 1941. Filho de pais judeus de origem polonesa, apesar de sua excepcional aptidão para as ciências, optou pela filosofia. Exprime, em nível filosófico, um novo paradigma baseado na consciência, adquirido pela cultura de seu tempo, das conexões entre a vida orgânica e a vida social e psíquica.

Escritor do livro Matéria e Memória, observamos que Henri Bergson destaca importantes conceitos que potencializam as análises sobre a memória e sua relação com as imagens. Henri Bergson foi um intelectual francês, formado em Letras, que se dedicou a estudos filosóficos de cunho fenomenológico e produziu obras de referência como Ensaios sobre os dados imediatos da consciência (1889), Matéria e Memória (1896), A Evolução Criadora (1907) e Duração e Simultaneidade (1918).

A complexidade na definição e concretização do termo Memória não é somente relembrar o passado e muito menos buscar lugares, encontros, pessoas no codidiano da vida. Para Silva (2003) a palavra memória provém do grego que diz, mais imediatamente, ação de lembrar, o lembrar dele mesmo, aquilo que permanece no espírito. Dentro desse pressuposto, pode-se entender á memória como instância de inventar, meditar, refletir e velar, no sentido de cuidar.

A memória na concepção de Bergson é um fenômeno que responde pela reelaboração do passado no presente, "ela prolonga o passado no presente" (Bergson, 2006, p.247), e "é do presente que parte o apelo ao qual a lembrança responde, e é do elemento sensório-motor da ação, que a lembrança retira o calor que lhe confere vida" (Bergson, 2006, p. 179). Para este Filósofo, a lembrança é "a representação de um objeto ausente" (Bergson, 1999, p.80; p.275). Ele ainda 
escreve,

[...] A memória, praticamente inseparável da percepção, intercala o passado no presente, condensa também, numa intuição única, momentos múltiplos da duração e, assim, por sua dupla operação, faz com que de fato percebamos a matéria em nós, enquanto de direito a percebemos nela (BERGSON, 1999, p.77).

A sua obra Matéria e memória (1939) será de grande valia para este estudo por elucidarmos questões acerca da memória do corpo nos espaços sagrados, destacando o modo pelo qual Bergson irá pensar a memória como sendo, principalmente, virtualidade, potencialidade de formas e de sentidos, nesses estudos é relevante que valorize justamente a dimensão do informe e da forma em sua relação com a criação.

Enquanto outros oporiam ao racionalismo a subjetividade ou a história, Bergson tem uma visão nova (que também o distancia de Hegel) da dialética e da existência, Bergson constrói a sua filosofia sobre quatro ideias fundamentais: a "intuição", a "durée", a "memória" e o "élan vital".

Em seus escritos, para Bergson, a filosofia não só se distingue da ciência, mas mantém as coisas uma relação que é o oposto da relação científica. Uma é o conhecimento do absoluto, e outra, do relativo. Um absoluto não poderia ser dado senão numa intuição, ao passo que todo o resto depende da análise. Bergson chama de "intuição" essa espécie de simpatia intelectual pela qual nos transportamos ao interior de um objeto para coincidir com aquilo que ele tem de único e, por conseguinte, de inexprimível.

Para Bergson, a inteligência conceitual desloca a realidade do tempo para o espaço, suprimindo o fluxo que a constitui fixando-lhe contornos precisos e permanentes, através dos quais ela se torna suscetível de ser definida e utilizada. Nesse caso, a "durée" é materializada.

Depois de estudar a alteração, através da qual a "durée" se diversifica, Bergson procura identificar o processo oposto: o da unificação, o reencontro do simples como uma convergência de probabilidade. O élan vital é a virtualidade da "durée". Como uma gerbe (um feixe), cria direções diferentes pelo simples fato de crescer. A memória integra os diferentes momentos da "durée", absolutamente diferentes entre si, mas unificados numa totalidade movente.

Para o filósofo toda percepção é memória. "Nós só percebemos, praticamente, o passado, o presente puro a roer o futuro sendo o inapreensível 
avanço do passado" (Bergson, 2006, p. 50). Para Bergson tudo está no tempo, não sendo este tempo apenas através do espaço, mas como ele escreve a duração real sendo aquela que morde as coisas e nelas e deixa a marca de seus dentes ainda para ele, a duração é criação contínua e ininterrupta de diferenças.

A cada passo que damos, a cada trajeto que percorremos, rememoramos dentro do terreiro que pertencemos, recebemos a força e energia vital que emana das yabás em especial Oxum, a forma de como aprendemos e adquirimos 0 conhecimento através da repetição e incorporação dessa entidade, que se torna uma tradição perpassando dos mais velhos para os mais novos.

Portanto as lembranças se efetivam através da memória-hábito, onde criam as inspirações, as memorizações, os pensamentos, as ideias, anseios, sentimentos, e outras sensações mais pessoais que dão origem através do reconhecimento pela via de ação nas quais (re) criam, através de conjuntos de imagens ao encontro da natureza, conciliando a imagem percebida com a imagem lembrada.

Uma das construções civilizatórias dos povos africanos em solo brasileiro de grande riqueza cultural é o candomblé. Podemos dizer que o candomblé é uma religião de matriz africana. Herdamos das diversas etnias africanas que fizeram a travessia do atlântico no período colonial alimentando o sistema econômico escravista brasileiro a parti do deslumbramento por parte da coroa portuguesa e comerciantes/traficantes que perceberam uma forma lucrativa na exploração de especiarias e de pessoas africanas. Essa diáspora forçada dos povos africanos para - Brasil que durou oficialmente três séculos e clandestinamente mais meio século (1502 a 1860), inúmeros povos desembarcaram na Bahia: sudaneses: (iorubás, gegês e fanti-ashantis); guinenos-sudaneses muçulmanos: (fula, mandinga, haussas e tapas) e bantus: (angola-congoleses e moçambiques) (GASPARETTO JR, A., 2009).

Esses povos vindos de diversas partes da África foram batizados na religião cristã, mas suas ligações às antigas crenças permaneceram. Essas associações thes permitiam manifestar suas cantigas, rezas e danças, que aos olhos dos senhores, pareciam simples distrações de negros e negras nostálgicos/as. Mas, na realidade, tratava-se das reuniões nas quais eles evocavam suas deusas e deuses 3 .

Dessa forma, herdamos suas construções civilizatórias e uma delas é o

${ }^{3}$ Conhecidos popularmente como Orixás, cada deus africano representa uma energia da natureza. Eles são cultuados nas religiões de origem africana, Umbanda e Candomblé. 
candomblé. Podemos dizer que o candomblé é uma religião que congrega valores dessas diversas etnias africanas. Como define Baçan (2012) "culto Afrobrasileiro" que o distingue pelas suas designações regionais: candomblés na Bahia; xangôs em Pernambuco; tambores em São Luís do Maranhão; candomblés de caboclo na faixa litorânea, da Bahia ao Maranhão; catimbós no Nordeste; batuques ou parás no Rio Grande do Sul e Santa Catarina e Paraná; batuques e babaçuês no Amazonas, Pará e Maranhão.

O termo candomblé vem de kandombele e significa "rezar ou pedir intercessão dos deuses". Apesar de o candomblé ser de procedência iorubá e se organizar nos moldes das tradições desses povos, os terreiros de candomblé têm sua origem no Brasil (VERGER, 1997). Muitos povos africanos contribuíram para a formação dos terreiros, entre eles os Ekiti, que cultuavam o Orixá Ogum (em iorubá: Ògún) e os Ixeja, que cultuavam Oxalá. Segundo Piere Verger (1997), os terreiros de candomblé não devem ser caracterizados apenas como um espaço de culto aos orixás, mas, principalmente, como um lugar de resistência cultural, que busca preservar as tradições dos diversos povos africanos trazidos para $\circ$ Brasil $e$ compartilhado em suas comunidades.

O culto aos Orixás ou batuques como era denominado passou e passa por perseguições das mais diversas formas, o que impediu por muito tempo a liberdade religiosa para os povos africanos e para os povos afro-brasileiros, porém o candomblé, seguimento religioso fundado no Brasil para cultuar as divindades africanas, foi tendo seu culto permitido à custa de muita luta e militância e teve como resultado uma maior liberdade de culto às divindades africanas, o que foi crucial para manter viva a religiosidade, tradição e línguas "yorubana", especificamente, já que o culto aos Orixás pertence a esses povos. Mesmo os povos negros sendo e catequizados na religião cristã, sua ligação às antigas crenças permaneciam, o que permitiu que essa religiosidade se mantivesse viva no Brasil até hoje.

No cotidiano dos adeptos do candomblé de tradição "yorubá" no Brasil são utilizados termos, frases, provérbios, cantigas e rezas todos na língua natural. Nestes espaços estão conservados e resinificados valores de legado africano através da luta contra a escravidão que resulta através da afirmação existencial do/da negro/a, que implica na continuidade transatlântica de sues princípios e valores transcendentes. 
Um dos aspectos dos saberes e fazeres dessas instituições religiosas de legado africano é a dança. Através da dança as pessoas iniciadas no candomblé reverenciam o sagrado. Uma forma também de ligar-se com o cosmo do Orum ao Aiyé4.

\section{A MEMÓRIA QUE ACALMA}

Oxum dança para Ogum na floresta e o traz de volta à forja, perante Obatalá, Ogum havia condenado a si mesmo a trabalhar duro na forja para sempre. Mas ele estava cansado da cidade e da sua profissão. Queria voltar a viver na floresta, voltar a ser livre caçador que fora antes. Ogum achava-se muito poderoso, sentia que nenhum orixá poderia obriga-lo a fazer o que não quisesse. Ogum estava cansado do trabalho de ferreiro e partiu para a floresta, abandonando tudo. Logo que os orixás souberam da fuga de Ogum, foram a seu encalço para convencê-lo a voltar à cidade e à forja, pois ninguém podia ficar sem os artigos de ferro de Ogum, as armas, os utensílios, as ferramentas agrícolas. Mas Ogum não ouvia ninguém, queria ficar no mato. Simplesmente os enxotava da floresta com violência. Todos lá foram menos Xangô. E como estava previsto, sem os ferros de Ogum, o mundo começou a ir mal. Sem instrumentos para plantar, as colheitas escasseavam e a humanidade já passava fome. Foi quando uma bela e frágil jovem veio à assembleia dos orixás e ofereceu-se a convencer Ogum a voltar à forja. Era Oxum a bela jovem voluntária. Os outros orixás escarnearam dela, tão jovem, tão bela, tão frágil. Ela seria escorraçada por Ogum e até temiam por ela, pois Ogum era violento, poderia machuca-la, até mata-la. Mas Oxum insistiv, disse que tinha poderes de que os demais nem suspeitavam. Obatalá, que tudo escutava mudo, levantou a mão e impôs silêncio. Oxum o convencera, ela podia ir à floresta e tentar. Assim, Oxum entrou no mato e se aproximou do sítio onde Ogum costumava acampar. Usava-a tão somente cinco lenços transparentes presos à cintura em laços, como esvoaçante saia. Os cabelos soltos, os pés descalços, Oxum dançava como vento e seu corpo desprendia um perfume arrebatador. Ogum foi imediatamente atraído, irremediavelmente conquistado pela visão maravilhosa., mas se manteve distante. Ficou à espreita atrás dos arbustos, absorto. De lá admirava Oxum embevecido. Oxum o via, mas fazia de conta que não. O tempo todo ela dançava e se aproximava dele, mas fingia sempre que não dera por sua presença. A dança e o vento faziam flutuar os cinco lenços da cintura, deixando ver por segundos a carne irresistível de Oxum Ela dançava, o enlouquecia. Dele se aproximava e com seus dedos sedutores lambuzavam de mel os lábios de Ogum. Ele estava como que em transe. E ela o atraía para si e ia caminhando pela mata, sutilmente tomando a direção da cidade. Mais dança mais mel, mais sedução, Ogum não se dava conta do estratagema da dançarina. Ela ia à frente, ele a acompanhava inebriado, louco de excitação. Quando Ogum se deu conta, eis que se encontravam ambos na praça da 
cidade. Os orixás todos estavam lá e aclamavam o casal em sua dança de amor. Ogum estava na cidade, Ogum voltara! Temendo ser tomado como fraco enganado pela sedução de uma mulher bonita, Ogum deu a entender que voltara por gosto e vontade própria. E nunca mais abandonaria a cidade. E nunca mais abandonaria sua forja. E os orixás aplaudiam e aplaudiam a dança de Oxum. Ogum voltou à forja e os homens voltaram a usar seus utensilios e houve plantações e colheitas e a fartura baniu a fome e espantou a morte. Oxum salvara a humanidade com sua dança de amor (PRANDI, 2001 p. 323).

Quando se entra em transe, a divindade Oxum é (re) conhecida através da movimentação sensual e cadenciada de ombros e braços, segurando suavemente uma espécie de lenço que envolve o pescoço e cai à frente do corpo. Os seus movimentos próprios da dança, representa a calmaria das águas, com passos lentos e cuidadosos para externar a sua beleza e paciência, no momento em que ela banha em suas águas, ela dobra os joelhos, como se estivesse imergindo nas águas, penteando os cabelos e olhando para o Abebé5, não só para admirar a sua beleza, mas para se proteger contra adversários que lutam atrás das costas.

Nessa direção, Bergson irá apontar que o corpo, enquanto matéria viva escolhe o modo de devolver os estímulos que recebe: "meu corpo é, portanto, no conjunto do mundo material, uma imagem que atua como as outras imagens, recebendo e devolvendo movimento" (BERGSON, 1999, pág. 71).

Na dança da Orixá Oxúm, não podem faltar os movimentos dos seus braços apresentando o adorno de suas pulseiras e colares dourados afirmando ser a dona da riqueza e prosperidade, suas saias são arrumadas com bastantes anáguas, para que possa ter um balanceio suave. Um movimento interessante é quando Oxum sente as contrações do parto de seu filho Logunedéb. É nesse momento que Oxum convida Logunedé para dançar juntos quando está na beira do rio, até mesmo quando Oxum acaricia seu filho nas águas doce.

Nessa direção, Bergson irá apontar que o corpo, enquanto matéria viva escolhe o modo de devolver os estímulos que recebe: "meu corpo é, portanto, no conjunto do mundo material, uma imagem que atua como as outras imagens,

\footnotetext{
5 Espelho que ela traz em suas mãos.

6 Orixá masculino da pesca e da caça, considerado um dos mais belos. Ele herdou o jeito meigo e a graça de Oxum e a felicidade e o espírito caçador de seu pai Oxóssi, portanto Logunedé apresenta em suas características expressões femininas e masculinas, o que o faz aparecer em como uma figura jovem.
} 
recebendo e devolvendo movimento" (BERGSON, 1999, pág. 71). Isso nos conduz compreender que atavés do processo, das atuações da percepção e da consciência na imbricada relação com estímulos é que Bergson vai denominar intervalo de movimento.

Tal intervalo é intuído na sua determinação pelo fato do presente durável ser pleno de antecipações e carregado de retenções, compondo um fluxo vibracional que habilita a hesitação existente em todo aquele que escolhe entre as percepções reais a resposta possível a ser executada pela ação motriz (MARCIEL, 2017, p. 7).

Encontram-se, geralmente, separados do espaço destinado às danças sagrada e à assistência, pequenas muretas ou cordas, para que os/as Orixás possam se movimentar com passos particulares de cada um/uma. Para Bergson, o movimento é heterogêneo em sua realidade temporal: "A duração faz do movimento mudança, heterogeneidade, se a matéria é um conjunto de imagens móveis, das interações destas imagens resultará uma valorização qualitativa" (MACIEL, 1997 p.27).

Aprender a cantar, dançar e pronunciar aplicado as diferentes saudações dirigidas aos mais velhos e aos orixás é "reconhecer por intermédio direto da memória de lembranças" que se faz necessário para os que se desejam e querem se adentrar aos terreiros de Axé e buscam "verificar um aprofundamento simultâneo em níveis da realidade espiritual" vivenciados na religião dos deuses africanos, Bergson diz:

Na operação prática a utilização da experiência passada para a ação presente... - o reconhecimento -deve realizar -se duas maneiras. Ora se fará na própria ação e pelo funcionamento do mecanismo apropriado às circunstâncias; ora implicará um trabalho do espirito, que irá buscar no passado para dirigi-las ao presente as representações mais capazes de se inserirem na situação atual (BERGSON, 1990, p.176).

O que dá sentido à percepção da matéria é o corpo vivo e este, carrega consigo a capacidade de trazer ao presente à porção conservada do seu passado, portanto os conhecimentos são transmitidos passando dos mais velhos para os mais novos, quando os primeiros reconhecem a capacidade e os consideram socialmente identificados como filhos/as da casa, sendo permitidos por sua vez, a transmitir o saber. O conhecimento "vem com o tempo", dizem os 
mais antigos. Assim, através de um processo lentamente adquirido, o saber do novo iniciado, encrusta-se no mais profundo do seu ser (Cossard-Binon, 1981).

\begin{abstract}
A memória do corpo, constituída pelo conjunto dos sistemas sensório motores que o habito organizou, é, portanto, uma memória quase instantânea a qual a verdadeira memória do passado serve de base. Como elas não constituem duas coisas separadas, como a primeira não é, dizíamos, senão a ponta móvel, inserida pela segunda no plano movente da experiência, é natural que essas duas funções prestem-se mútuo apoio (BERGSON, 1999, p.178).
\end{abstract}

Essas memórias contidas na dança em seus corpos incorporados pelos/as orixás transmitem as suas narrativas míticas, podendo ser aplicada na força espiritual que constribui para a resistência e sobrevivência nos terreiros de candomblé. A percepção desses objetos, por sua vez, provoca em nós certas reações (movimentos nascentes) que, ao se repetirem, se organizam entre si formando hábitos corporais. Esses mecanismos motores respondem a um processo de adaptação que é a finalidade geral da vida, da qual se desprende tanto o sentido prático da ação, quanto o seu sentido vital (BERGSON, 1999).

O movimento corporal de filhas e filhos-de-santo no ritual é compreendido como um elemento integrador na comunicação com o sobre-humano e apresenta-se através da memória-hábito o conhecimento mítico dado a aquisição de uma gestualidade simbólica por meio da iniciação.

Meu corpo se conduz, portanto como uma imagem que refletiria outras imagens, analisando-as do ponto de vista das diversas ações a exercer sobre elas. E, por consequência, cada uma das qualidades percebidas por meus diferentes sentidos no mesmo objeto simboliza uma certa direção de minha atividade, uma certa necessidade. (BERGSON, 2006, p. 48)

A memória motora apresenta a sua ação tomando a sua forma, atarvés do reconhecimento a "percepção das semelhanças" visto que, segundo Bergson (1999), a semelhança entre coisas ou estados, que declaramos perceber, é antes de tudo a propriedade, comum a esses estados ou a essas coisas, de obter de nosso corpo a mesma reação, de fazê-lo esboçar a mesma atitude e começar os mesmos movimentos através dos gestos, os movimentos corporais, da linguagem de comunicação nas danças, independente de uma função específica. 


\section{CONSIDERAÇÕES FINAIS}

[...] o cérebro é uma imagem, os estímulos transmitidos pelos nervos sensitivos e propagados no cérebro são imagens também [...] é o cérebro que faz parte do mundo material, e não o mundo material que faz parte do cérebro [...] Nem os nervos nem os centros nervosos podem, portanto condicionar a imagem do universo (BERGSON, 1999 13-14p).

Procuramos construi uma pequena abordagem sobre a questão da dança sagrada na memória Bergonsiana através das comunidades de terreiros, compreendida como expressões corporais representadas através do movimento, da memória e na dança, relacionandas a matéria e memória trazida por $\mathrm{H}$. Bergson que nos ajudou a situar a memória motora, que imprime a marca da generalidade à sua ação e, assim, reconhecendo a "percepção das semelhanças" que é o fundamento das ideias gerais, visto que, segundo Bergson (1999), a semelhança entre coisas ou estados, que declaramos perceber, é antes de tudo a propriedade de obter nosso corpo a mesma reação, de fazê-lo esboçar a mesma atitude e começar os mesmos movimentos.

Diante da complexidade étnica, cultural e religiosa presentes nas comunidades de terreiros podem perceber que é impossível não relacionar a dança sagrada observada nos terreiros de candomblé, construída através da memória-hábito trazida por Bergson.

O estudo das danças de orixás, especificamente em Oxum, nos permite perceber e agir acerca da transposição dessas danças a outras manifestações dançantes que não sejam as específicas dos rituais de candomblé, mas que estão em outros espaços educacionais, sendo rememoradas por adeptos e não adeptos do candomblé, pois tudo que existe se move importante, destacar que o transe só pode acontecer em espaços sagrados, nos terreiros com a permissão dos maiorais. Além do mais, embora Oxum seja uma Orixá, o transe pode acontecer através das manifestações corpóreas que não impõem idade, gênero, etnia ou nacionalidade.

Essas manifestações da ritualística do candomblé precisam ser preservadas culturalmente e socialmente respeitando a heterogêneidade dela, não permitindo ser apagadas e silenciadas por uma sociedade que emprega inúmeras formas de desumanizar e separar os membros das famílias africanas que aqui foram trazidas; tratando de forma cruel, como seres inferiores e, assim, obrigando a perder a sua identidade, os costumes, a língua, a memória, culinária, conhecimentos 
tecnológicos e científicos, ou seja, a memória e cultura de seus ancestrais sendo fadados ao esquecimento.

\section{REFERÊNCIAS}

AUGRAS, Monique. A ordem na desordem: a regulamentação do desfile das escolas de samba e a exigência de motivos nacionais. [sd]. 2008.

BAÇAN, L.P. Dicionário dos rituais afro-brasileiros. Copyright: Londrina. 2012.

BERGSON, Henri. Matéria e memória. Trad. Paulo Neves. 2 a ed. São Paulo: Martins Fontes, 1999. Matéria e Memória: ensaio sobre a relação do corpo com o espírito. São Paulo: Martins e Fontes, 2006.

COOSARD-BINON, G. Olóòrisá. São Paulo: Ed. Ágora, 1981.

GASPARETTO Junior, Antônio. Origem dos escravos africanos, 2009. Disponível em: http://www.historiabrasileira.com/brasil-colonia/origem-dos-escravos-africanos/.

MACIEL. Auterives. O todo aberto: tempo e subjetividade em Henri Bergson. Dissertação de mestrado em filosofia. Rio de Janeiro Universidade Estadual do Rio de Janeiro, 1997. O todo aberto: duração e subjetividade em Henri Bergson. Livro, Ed: Arquimedes, 2017.

PRANDI, Reginaldo. Mitologia dos Orixás. São Paulo: Companhia das Letras, 2001.

SILVA. Alexandre Rocha da. Elementos para uma comunicação pósmidiática. São Paulo: Unisinos, 2003.

VERGER, P. Orixás - Deuses lorubás na África e no Novo Mundo. Salvador: Corrupio, 1997 